\title{
Penerapan Model Pembelajaran Cooperative Script untuk Meningkatkan Hasil Belajar IPS Siswa di SD Inpres Tumpu Jaya I
}

\author{
I Ketut Selamet \\ SD Inpres Tumpu Jaya 1, Kabupaten Banggai - Provinsi Sulawesi Tengah \\ Corresponding Author. Email: ketutselamet123164@gmail.com
}

\begin{abstract}
This study aims to improve social studies learning outcomes through a cooperative script learning model in grade VI SD Inpres Tumpu Jaya I. This research method uses classroom action research with a spiral model from Kemmis and Mc Taggart using 2 cycles. The subjects of this study were 22 students of grade VI SD Inpres Tumpu Jaya I. The research instrument used item items and observation sheets. The data analysis technique used is descriptive comparative. The results of this study indicate that there is an increase in student social studies learning outcomes after using the cooperative script learning model. This is based on the comparison of the average score, namely 70.62: 79.19: 87.48 which means that there is an increase from precycle to cycle II. Classical learning completeness in the conditions of pre-cycle, cycle I and cycle II, namely 50\%: $77.27 \%$ : 100\%. While the comparison of the minimum score in the pre-cycle conditions, cycle I and cycle II is 50: 65: 76, and the comparison of the maximum score in the pre-cycle conditions, cycle I and cycle II is 82: 90: 100. From the results of this study it can encourage class VI teachers. SD Inpres Tumpu Jaya I should be inspired to apply the cooperative script learning model in social studies learning because it has been proven to improve student social studies learning outcomes.
\end{abstract}

\begin{abstract}
Abstrak: Penelitian ini bertujuan untuk meningkatkan hasil belajar IPS melalui model pembelajaran cooperative script pada siswa kelas VI SD Inpres Tumpu Jaya I. Metode penelitian ini menggunakan penelitian tindakan kelas dengan model spiral dari Kemmis dan Mc Taggart dengan menggunakan 2 siklus. Subyek penelitian ini adalah siswa kelas VI SD Inpres Tumpu Jaya I sebanyak 22 siswa. Instrumen penelitiannya menggunakan butir-butir soal dan lembar observasi. Teknik analisis data yang digunakan adalah deskriptif komparatif. Hasil penelitian ini menunjukkan bahwa ada peningkatan hasil belajar IPS siswa setelah menggunakan model pembelajaran cooperative script. Hal ini didasarkan pada perbandingan skor rata-rata yakni 70,62 : 79,19: 87,48 yang berarti ada peningkatan dari prasiklus ke siklus II. Ketuntasan belajar klasikal pada kondisi pra siklus, siklus I dan siklus II yakni 50\%: 77,27\% : $100 \%$. Sedangkan perbandingan skor minimal pada kondisi prasiklus, siklus I dan siklus II yakni sebesar $50: 65: 76$, dan perbandingan skor maksimal pada kondisi prasiklus, siklus I dan siklus II yakni 82 : 90 : 100. Dari hasil penelitian ini dapat mendorong guru kelas VI SD Inpres Tumpu Jaya I agar terinspirasi untuk menerapkan model pembelajaran cooperative script pada pembelajaran IPS karena terbukti dapat meningkatkan hasil belajar IPS siswa.
\end{abstract}

Article History

Received: 08-02-2021

Revised: 09-03-2021

Published: 04-04-2021

\section{Key Words:}

Cooperative Script, Learning Outcomes, Social Studies.

\section{Sejarah Artikel}

Diterima: 04-02-2021

Direvisi: 09-03-2021

Diterbitkan: 04-04-2021

Kata Kunci:

Cooperative Script, Hasil

Belajar, IPS.

How to Cite: Selamet, I. (2021). Penerapan Model Pembelajaran Cooperative Script untuk Meningkatkan Hasil Belajar IPS Siswa di SD Inpres Tumpu Jaya I. Jurnal Paedagogy, 8(2). doi:https://doi.org/10.33394/jp.v8i2.3493

https://doi.org/10.33394/jp.v8i2.3493

This is an open-access article under the CC-BY-SA License.

\section{Pendahuluan}

Ilmu Pengetahuan Sosial adalah program pendidikan yang mengintegrasikan secara interdisiplin konsep ilmu-ilmu sosial dan humaniora. Ilmu pengetahuan sosial lahir dari keinginan para pakar pendidikan untuk membekali para siswa supaya nantinya mereka 
mampu menghadapi dan menangani kompleksitas kehidupan di masyarakat yang seringkali berkembang secara tidak terduga (Susilo dkk, 2009; Arbaiyah, 2020). Sedangkan menurut Hidayati dkk (2008) pada dasarnya IPS merupakan kajian tentang manusia dan dunia sekelilingnya. Yang menjadi kajian IPS ialah tentang hubungan antar manusia (Sapriya, 2009). Latar telaahnya adalah kehidupan nyata manusia (Selamet, 2020; Najamudin, 2020).

Berbagai penelitian menunjukan bahwa masih banyak permasalahan pelaksanaan standar isi mata pelajaran IPS (Rafikah, 2019; Bera, 2018). Guru dalam menerapkan pembelajaran lebih menekankan pada metode yang mengaktifkan guru, kurang melibatkan peserta didik, pembelajaran yang dilakukan guru kurang kreatif, lebih banyak menggunakan metode konvensional (ceramah) dan kurang mengoptimalkan media pembelajaran. Sehingga siswa kurang aktif dalam mengikuti proses pembelajaran, bahkan cenderung pasif. Siswa hanya diam saja, mendengarkan, mencatat, dan mudah bosan dalam pembelajaran.

Permasalahan pada pembelajaran IPS juga terjadi pada siswa kelas VI SD Inpres Tumpu Jaya I, pembelajaran kurang berkualitas dimana dalam pelaksanaan pembelajaran masih sering dijumpai kendala yaitu siswa kesulitan memahami materi yang dipelajari, khususnya pada pembelajaran IPS tema Selamatkan Makhluk Hidup kompetensi dasar "Mengidentifikasi karakteristik geografis dan kehidupan sosial budaya, ekonomi, politik di wilayah ASEAN". Peran peserta didik tampak belum secara optimal diperlakukan sebagai subyek didik yang memiliki potensi untuk berkembang secara mandiri. Posisi peserta didik masih dalam situasi dan kondisi belajar yang menempatkan siswa dalam keadaan pasif. Aktivitas dan motivasi siswa dalam pembelajaran IPS masih sangat kurang sehingga mengakibatkan hasil belajar siswa rendah. Hal tersebut dikarenakan guru belum mengunakan model pembelajaran inovatif dan juga tidak menggunakan media dalam pembelajarannya.

Setelah dilakukan diskusi dengan kepala sekolah dan sekaligus sebagai kolaborator, untuk memecahkan masalah pembelajaran tersebut, tim kolaborasi menetapkan alternatif tindakan untuk meningkatkan kualitas pembelajaran, yang dapat mendorong keterlibatan siswa dalam pembelajaran dan meningkatkan kreativitas serta keterampilan guru. Salah satu model pembelajaran yang dipandang kondusif dapat meningkatkan efektivitas pembelajaran adalah model Cooperative Script. Untuk mengajarkan kompetensi dasar "Mengidentifikasi karakteristik geografis dan kehidupan sosial budaya, ekonomi, politik di wilayah ASEAN", siswa harus dapat mengerti dan memahami materi tentang macam-macam Mengidentifikasi karakteristik geografis dan kehidupan sosial budaya, ekonomi, politik di wilayah ASEAN yang materinya terhitung banyak sehingga memerlukan cara belajar dengan ringkas dan efisien. Di sini, siswa tidak dapat bekerja sendiri karena ide atau pendapat teman lain dibutuhkan agar saling melengkapi pengetahuan masing-masing. Selain itu, dalam materi Mengidentifikasi karakteristik geografis dan kehidupan sosial budaya, ekonomi, politik di wilayah ASEAN, dibutuhkan media yang menunjang pembelajaran, seperti gambar, suara, video ataupun film yang berkaitan dengan materi. Keunggulan dari model Cooperative Script terjadi kesepakatan antara siswa tentang aturan-aturan dalam berkolaborasi. Masalah yang dipecahkan bersama akan disimpulkan bersama. Peran guru hanya sebagai fasilitator yang mengarahkan siswa untuk mencapai tujuan belajar. Pada interaksi siswa terjadi kesepakatan, diskusi, menyampaikan pendapat dari ide-ide pokok materi, saling mengingatkan dari kesalahan konsep yang disimpulkan, membuat kesimpulan bersama. Interaksi belajar yang terjadi benar-benar interaksi dominan siswa dengan siswa. Dalam aktivitas siswa selama pembelajaran IPS dengan menggunakan model pembelajaran Cooperative Script benar-benar memberdayakan potensi siswa untuk mengaktualisasikan 
pengetahuan dan keterampilannya, jadi benar-benar sangat sesuai dengan pendekatan konstruktivisme yang dikembangkan saat ini.

Melalui model pembelajaran Cooperative Script dengan media audiovisual diharapkan dapat menambah aktivitas siswa dalam proses pembelajaran dan meningkatkan hasil belajarnya sehingga kualitas pembelajaran IPS akan meningkat. Model pembelajaran Cooperative Script merupakan penyampaian materi ajar yang diawali dengan pemberian wacana atau ringkasan materi ajar kepada siswa yang kemudian diberikan kesempatan kepada siswa untuk membacanya sejenak dan memberikan/memasukkan ide-ide atau gagasan-gagasan baru ke dalam materi ajar yang diberikan guru, lalu siswa diarahkan untuk menunjukkan ide-ide pokok yang kurang lengkap dalam meteri yang ada secara bergantian sesama pasangan masing-masing (Indien: 2012). Keunggulan daripada model pembelajaran ini di antaranya: (1) melatih kemampuan berbicara, (2) melatih pendengaran, ketelitian atau kecermatan, (3) setiap peserta didik mendapat peran, (4) melatih mengungapkan kesalahan orang lain dengan lisan (Suryaningsih: 2010). Hal ini sangat sesuai diterapkan dalam pembelajaran IPS khusunya materi Mengidentifikasi karakteristik geografis dan kehidupan sosial budaya, ekonomi, politik di wilayah ASEAN dimana di dalamnya dibutuhkan media berupa gambar tentang karakteristik geografis dan kehidupan sosial budaya, ekonomi, politik di wilayah ASEAN.

Adapun penelitian ini bertujuan untuk meningkatkan hasil belajar IPS Tema Selamatkan Makhluk Hidup melalui model pembelajaran cooperative script pada siswa kelas VI SD Inpres Tumpu Jaya I.

\section{Metode Penelitian}

Penelitian ini menggunakan metode penelitian tindakan kelas, menggunakan model spiral Kemmis dan Targgart dengan menggunakan 2 siklus. Di dalam setiap siklus terdapat 3 tahap, yaitu: perencanaan (pembuatan RPP, lembar observasi, lembar evaluasi), implementasi RPP dan observasi, refleksi. Subyek dalam penelitian ini siswa kelas VI di SD Inpres Tumpu Jaya I yang berjumlah 11 siswa. Teknik pengumpulan data yang dipakai dalam penelitian tindakan ini adalah teknik tes dan non tes yang berupa unjuk kerja. Instrumen penelitian adalah butir-butir soal dan lembar observasi unjuk kerja serta lembar observasi implementasi RPP.

Teknik analisis data yang digunakan adalah teknik diskriptif komparatif yang merupakan teknik statistik dengan membandingkan hasil penelitian antar siklus yaitu mean, skor minimal, skor maksimal, stardar deviasi dan persentase. Indikator kinerja dalam penggunaan PTK ini dinyatakan dapat berhasil meningkatkan hasil belajar siswa apabila ketuntasan klasikal sebesar $85 \%$ dari jumlah keseluruhan siswa kelas VI mendapatkan nilai $\geq 76$ sebagai hasil belajar mata pelajaran IPS tema selamatkan makhluk hidup pada tahap evaluasi akhir sesuai KKM 76 serta keaktifan siswa yang juga turut diamati dan dinilai.

\section{Hasil Penelitian dan Pembahasan Deskripsi Siklus I}

Berdasarkan hasil analisis data dari penelitian yang dilaksanakan di SD Inpres Tumpu Jaya I Tahun Pelajaran 2020/2021 pada kelas VI terlihat bahwa telah terjadi peningkatan pada hasil belajar siswa setelah diadakan pembelajaran dengan penggunaan model pembelajaran kooperatif tipe cooperative script, dengan nilai rata-rata 70,62 sebelum diadakan penelitian dan setelah diadakan penelitian pada Siklus I nilai rata-rata menjadi 79,19 . Berarti pembelajaran telah berhasil baik dengan jumlah siswa yang nilainya tuntas dari 
KKM 76 sebanyak 8 siswa dengan tingkat keberhasilan $72,72 \%$ dari jumlah siswa sebanyak 11 siswa, dan pada Siklus I ini sudah terjadi peningkatan hasil belajar, tetapi masih ada siswa yang belum tuntas sebanyak 3 siswa dengan persentase 27,27 \%. Hal tersebut dikarenakan siswa belum terlihat antusias dalam kegiatan pembelajaran karena mereka belum terbiasa pada penggunaan model pembelajaran cooperative script, ada pula siswa yang belum siap mengikuti pelajaran karena mereka belum jelas tentang apa yang harus mereka lakukan, selain itu mobilitas guru dalam membimbing siswa juga belum maksimal. Penelitian ini tidak sepenuhnya dilaksanakan sesuai dengan apa yang telah direncanaan, ada beberapa kendala yang mempengaruhi penelitian sehingga penelitian ini belum maksimal. Misalnya adanya siswa yang bercanda disaat diskusi kelompok berlangsung dan beberapa penjelasan serta perintah dari guru kurang tidak tegas sehingga siswa kurang memperhatikan tetapi mereka malah berbicara dengan teman yang lain di saat guru memberi perintah atau penjelasan kepada siswa.

\section{Deskripsi Siklus II}

Berbagai hal yang merupakan kekurangan yang ada pada Siklus I diperbaiki pada siklus II. Kegiatan yang dilakukan pada Siklus II ini masih sama dengan pertemuan sebelumnya yaitu pada siklus I. pada pembelajaran di Siklus II siswa sudah antusias dalam mengikuti kegiatan pembelajaran. Hasil dari siklus II, siswa telah mengalami peningkatan hasil belajar pada mata pelajaran IPS dengan persentase 100\%. Siswa tersebut telah tuntas dengan patokan nilai KKM yang telah ditentukan yaitu 76, dari 11 siswa semuanya telah menjapai ketuntasan yang telah ditetapkan. Pada siklus II rata-rata kelas menjadi 87,48 dengan nilai tertinggi 100 dan nilai terendah 76 .

Berdasarkan hasil pengamatan selama proses pembelajaran berlangsung, partisipasi siswa dalam pembelajaran cukup besar. Siswa lebih aktif mengikuti proses pembelajaran dan lebih aktif menjawab pertanyaan dari guru serta lebih berani mengemukakan pendapat. Dengan penggunaan model pembelajaran kooperatif tipe cooperative script ternyata telah memberikan antusias besar kepada siswa di dalam proses pembelajaran pada mata pelajaran IPS. Hal ini terlihat dari peningkatan hasil belajar siswa pada mata pelajaran IPS. Setelah dilakukan siklus I dan siklus II dengan siklus I sebanyak 2 kali pertemuan dan siklus II sebanyak 2 kali pertemuan, dapat meningkatkan pemahaman siswa dalam pembelajaran IPS .

Berdasarkan hasil tindakan dapat diketahui telah terjadi keberhasilan dalam menggunakan model pembelajaran cooperative script pada mata pelajaran IPS khususnya kompetensi dasar mengidentifikasi karakteristik geografis dan kehidupan sosial budaya, ekonomi, politik di wilayah ASEAN di kelas VI SD Inpres Tumpu Jaya I Kecamatan Batui Selatan Tahun Pelajaran 2020/2021. Keberhasilan tersebut dapat dilihat pada tabel dibawah ini.

Tabel 1. Perbandingan Hasil Belajar IPS Pada Pra Siklus, Siklus I, Siklus II

\begin{tabular}{|c|c|c|c|c|c|c|c|}
\hline Ketuntasan & \multirow{2}{*}{$\begin{array}{c}\text { Belajar } \\
\text { Skor }\end{array}$} & \multicolumn{2}{|c|}{ Pra Siklus } & \multicolumn{2}{c|}{ Siklus I } & \multicolumn{2}{c|}{ Siklus II } \\
\hline Tidak Tuntas & $<76$ & 5 & 45,45 & 3 & 27,27 & 0 & 0 \\
\hline Tuntas & 276 & 6 & 54,54 & 8 & 72,72 & 11 & 100 \\
\hline \multicolumn{2}{|c|}{ Jumlah } & 11 & 100 & 11 & 100 & 11 & 100 \\
\hline
\end{tabular}

Berdasarkan tabel diatas bahwa perbandingan hasil pembelajaran kompetensi dasar mengidentifikasi karakteristik geografis dan kehidupan sosial budaya, ekonomi, politik di wilayah ASEAN dan mengidentifikasi karakteristik geografis dan kehidupan sosial budaya, 
ekonomi, politik di wilayah ASEAN dapat dijelaskan bahwa pada kondisi awal ada 5 siswa $(45,45 \%)$ yang belum tuntas karena mendapat nilai di bawah KKM 76, sedangkan 6 siswa $(54,54 \%)$ telah tuntas karena mendapat nilai di atas KKM 76. Pada kondisi awal nilai tertinggi yang dicapai 82 dan nilai terendahnya 50. Karena terdapat 45,45\% siswa yang belum tuntas maka digunakan model pembelajaran cooperative script.

Pada hasil belajar Siklus I terlihat peningkatan hasil belajar kompetensi dasar tentang mengidentifikasi karakteristik geografis dan kehidupan sosial budaya, ekonomi, politik di wilayah ASEAN. Siswa kelas VI SD Inpres Tumpu Jaya I Kecamatan Batui Selatan telah mencapai hasil belajar kompetensi dasar mengidentifikasi karakteristik geografis dan kehidupan sosial budaya, ekonomi, politik di wilayah ASEAN 72,72 \% karena dari 11 siswa yang memperoleh nilai yang mencapai Kriteria Ketuntasan Minimal (KKM) 76 sebanyak 8 siswa dan 3 siswa lainnya masih memperoleh nilai di bawah KKM 76. Pada Siklus I ini nilai tertinggi yang dicapai siswa adalah 90 dan nilai terendah 65 . Kemudian tindakan dilanjutkan dengan Siklus II. hasil belajar siswa dalam pembelajaran IPS kompetensi dasar mengidentifikasi karakteristik geografis dan kehidupan sosial budaya, ekonomi, politik di wilayah ASEAN siswa mencapai 100\%. Dalam Siklus II nilai tertinggi yang diperoleh siswa 100 dan nilai terendahnya 76. Pembelajaran IPS kompetensi dasar mengidentifikasi karakteristik geografis dan kehidupan sosial budaya, ekonomi, politik di wilayah ASEAN telah dicapai sesuai dengan indikator kinerja yang peneliti harapkan yaitu $85 \%$ dari jumlah siswa keseluruhan mendapatkan nilai $\geq 76$ sesuai KKM 76 sebagai hasil belajar mata pelajaran IPS. Hasil belajar IPS secara umum sudah berhasil walaupun peningkatannya tidak bisa mencapai $100 \%$ dari jumlah siswa keseluruhan siswa yang mengikuti tes, namun siswa yang memperoleh nilai lebih dari atau sama dengan KKM yang ditentukan yaitu 76 sebanyak 11 siswa (100\%) yang berarti indikator inerja yang peneliti harapkan telah terlampaui.

Berdasarkan hasil penelitian di atas maka dapat diketahui bahwa telah terjadi peningkatan hasil belajar pada kompetensi dasar mengidentifikasi karakteristik geografis dan kehidupan sosial budaya, ekonomi, politik di wilayah ASEAN dengan kompetensi dasar mengidentifikasi karakteristik geografis dan kehidupan sosial budaya, ekonomi, politik di wilayah ASEAN dan materi setelah siswa mengikuti proses pembelajaran dengan menerapkan model pembelajaran cooperative script. Hasil belajar siswa berdasarkan tes formatif dan penilaian proses dari Siklus I dan Siklus II selalu mengalami kenaikan.

Selain pada tingkat ketuntasan hasil belajar yang meningkat, rata-rata hasil belajar IPS juga mengalami peningkatan dari hasil pra siklus 70,62 , ke siklus I menjadi 79,19 dan ke siklus II sebesar 87,48. Adapun perolehan skor maksimal juga mengalami peningkatan dari hasil pra siklus sebesar 82 meningkat menjadi 90 pada siklus I dan mengalami peningkatan kembali pada siklus II sebesar 100. Pada perolehan skor minimal juga mengalami peningkatan dari hasil pra siklus 50 meningkat menjadi 65 pada siklus I dan mengalami peningkatan kembali pada siklus II sebesar 76 .

\section{Kesimpulan}

Berdasarkan hasil penelitian dan pembahasan maka dapat disimpulkan bahwa melalui penggunaan model pembelajaran kooperatif tipe cooperative script dapat meningkatkan hasil belajar IPS siswa pada tema selamatkan makhluk hidup di kelas VI SD Inpres Tumpu Jaya I. Hal ini didasarkan pada perbandingan skor rata-rata pra siklus, siklus I dan siklus II yakni 70,62 : 79,19 : 87,48 yang berarti ada peningkatan dari prasiklus ke siklus I dan dari prasiklus ke siklus II. Ketuntasan belajar klasikal pada kondisi pra siklus, siklus I dan 
siklus II yakni 50\%: $77,27 \%: 100 \%$. Sedangkan perbandingan skor minimal pada kondisi prasiklus, siklus I dan siklus II yakni sebesar $50: 65: 76$, dan perbandingan skor maksimal pada kondisi prasiklus, siklus I dan siklus II adalah 82 : 90 : 100. Selain itu, berbagai permasalahan yang terjadi pada siswa pada saat pembelajaran berlangsung seperti siswa yang asik berbicara dengan teman ketika pelajaran berlangsung, tidak dapat menjawab pertanyaan dari guru, tidak mengerjakan PR dan nilai yang tidak tuntas persentasenya sangat kecil karena telah teratasi dengan digunakannya model pembelajaran cooperative script yang telah terbukti dapat meningkatkan hasil belajar IPS siswa.

\section{Saran}

Adapun saran yang dapat disampaikan berdasarkan hasil penelitian ini antara lain adalah;

(1) Bagi Guru

Dengan dilaksanakannya penelitian ini guru bisa terinspirasi untuk menerapkan model pembelajaran kooperatif tipe cooperative script ini pada pembelajaran IPS karena terbukti dapat meningkatkan hasil belajar IPS siswa dan agar pelajaran di kelas lebih variatif serta dapat memberikan pengalaman baru bagi siswa dalam proses pemahaman materi pelajaran IPS.

(2) Bagi Siswa

Dengan digunakannya model pembelajaran kooperatif tipe cooperatif script para siswa diharapkan untuk lebih antusias dan aktif lagi dalam pembelajaran di kelas karena tujuan pembelajaran model kooperatif adalah untuk memaksimalkan keaktifan dan rasa sosial siswa dalam pembelajaran.

\section{Daftar Pustaka}

Arbaiyah, A. (2020). UPAYA PENINGKATAN HASIL BELAJAR MATA PELAJARAN IPS TERPADU DENGAN METODE KOPERATIF TIPE STAD. Jurnal Paedagogy, 2(2), 76-81. doi:https://doi.org/10.33394/jp.v2i2.3051

Bera, L. (2018). Peningkatan Partisipasi Belajar Mata Pelajaran IPS Melalui Strategi Pembelajaran Word Square pada Siswa Kelas VA SD Inpres Iligetang. Jurnal Kependidikan: Jurnal Hasil Penelitian dan Kajian Kepustakaan di Bidang Pendidikan, Pengajaran dan Pembelajaran, 4(2), 163-172. doi:https://doi.org/10.33394/jk.v4i2.1125

Hidayati, dkk. (2008). Pengembangan Pendidikan IPS SD. Jakarta: Direktorat Jenderal Pendidikan Tinggi Departemen Pendidikan Nasional

Najamuddin, M. (2020). PENGEMBANGAN PEMBELAJARAN DENGAN PEMBERIAN BALIKAN TERHADAP HASIL BELAJAR IPS SISWA. Jurnal Paedagogy, 2(1), 22-28. doi:https://doi.org/10.33394/jp.v2i1.3045

Rafikah, I. (2019). Peningkatkan Hasil Belajar Siswa pada Mata Pelajaran IPS dengan Menggunakan Metode Cooperative Integrated Reading and Composition (CIRC) di Kelas III MI NW Taman Pagesangan Mataram. Jurnal Kependidikan: Jurnal Hasil Penelitian dan Kajian Kepustakaan di Bidang Pendidikan, Pengajaran dan Pembelajaran, 5(1), 34-39. doi:https://doi.org/10.33394/jk.v5i1.1391

Sapriya. (2009). Pendidikan IPS: Konsep dan Pembelajaran. Bandung: PT. Remaja Rosdakarya

Selamet, I. (2020). Penggunaan Media Visual untuk Meningkatkan Hasil Belajar Mata Pelajaran IPS Siswa Kelas V SD Inpres Tumpu Jaya I. Jurnal Paedagogy, 7(2), 121-125. doi:https://doi.org/10.33394/jp.v7i2.2505 
Susilo, dkk. (2009). Kajian Ilmu Pengetahuan Sosial. Salatiga: Widya Sari

Wardani Naniek Sulistya, dkk. (2009). Asesmen Pembelajaran SD. Jakarta: Depdiknas.

Trianto. (2011). Model-model Pembelajaran Inovatif Berorientasi Konstruktivistik. Jakarta: Prestasi Pustaka.

Wena, Made. (2009). Strategi Pembelajaran Inovatif Kontemporer. Jakarta: Bumi Akasara 